ISSN 2072-6651

www.mdpi.com/journal/toxins

Article

\title{
Ochratoxin A and Aflatoxins in Liquorice Products
}

\author{
Amedeo Pietri *, Silvia Rastelli and Terenzio Bertuzzi \\ Istituto di Scienze degli Alimenti e della Nutrizione, Facoltà di Agraria, Università Cattolica del Sacro \\ Cuore, Via Emilia Parmense, 84 I-29100 Piacenza, Italy; E-Mail: terenzio.bertuzzi@ unicatt.it (T.B.) \\ * Author to whom correspondence should be addressed; E-Mail: amedeo.pietri@ unicatt.it; \\ Tel.: +39523 599264; Fax: +39523599259.
}

Received: 26 February 2010; in revised form: 9 April 2010 / Accepted: 19 April 2010 /

Published: 20 April 2010

\begin{abstract}
The occurrence of ochratoxin A (OTA) and aflatoxins (AFs) in liquorice products made in Italy was surveyed. Twenty-eight samples of dried liquorice extract and fifty-four of liquorice confectionery (liquorice content between 2 and 10\%) were collected from retail outlets located in northern Italy. After extraction and purification through an immunoaffinity column, OTA and AFs were analysed using both HPLC-FLD and HPLC-MS/MS. OTA occurred in all samples of dried liquorice extract and in $61 \%$ of samples of liquorice confectionery, showing very high values for the former (mean $89.6 \mu \mathrm{g} \mathrm{kg}^{-1}$, maximum value $990.1 \mu \mathrm{g} \mathrm{kg}^{-1}$ ), and relatively low levels for the latter (mean $0.96 \mu \mathrm{g} \mathrm{kg}^{-1}$, maximum value $8.3 \mu \mathrm{g} \mathrm{kg}^{-1}$ ). The contribution of dried liquorice extract to OTA intake appears to be non-negligible for children, who are potentially high consumers. AF contamination resulted very low: $\mathrm{AFB}_{1}$ was detected only in $15.8 \%$ of samples (maximum value $7.7 \mu \mathrm{g} \mathrm{kg}^{-1}$, mean 0.38 and $0.41 \mu \mathrm{g} \mathrm{kg}^{-1}$ for dried liquorice extract and liquorice confectionery, respectively); the other AFs were not detected. To our knowledge, it is the first time that $\mathrm{AFB}_{1}$ has been detected in liquorice extract samples.
\end{abstract}

Keywords: ochratoxin; aflatoxins; liquorice

\section{Introduction}

Liquorice (Glycyrrhizia glabra L.) is a perennial herbaceous plant; it is cultivated mainly in countries of the Mediterranean area, but it is also widespread in Germany, Russia, China and Australia. Liquorice is a widely consumed medicinal herb and a common dietary supplement; it is used either as 
a fresh or dry rhizome (root), or as a liquorice extract; the latter is obtained after treatment of roots with steam or hot water and following concentration of the extract, to produce a syrup-like material or a solid liquorice block. Liquorice derivatives are widely used for the preparation of confectionery and other food products.

Ochratoxin A (OTA) is a mycotoxin produced by various Aspergillus and Penicillium species [1]. Several studies have shown that the toxin has carcinogenic, nephrotoxic, immunotoxic, teratogenic, and possibly neurotoxic and genotoxic properties and it has also been associated with Balcan Endemic Nephropathy in humans [2-5]. OTA contaminates many foods, such as cereals and derived products, dried fruit, coffee, cocoa, some spices, wine, grape juice, beer and ripened pork products [6-9].

Aflatoxins (AFs: $\mathrm{AFB}_{1}, \mathrm{AFB}_{2}, \mathrm{AFG}_{1}, \mathrm{AFG}_{2}$ ) are produced primarily by Aspergillus flavus and $A$. parasiticus [1]. $\mathrm{AFB}_{1}$, the most toxic and widespread of $\mathrm{AFs}$, is a potent genotoxic carcinogen in laboratory animals and there is strong evidence that it is a liver carcinogen in humans [10]. AF contamination concerns mainly dried fruit (nuts, peanuts, pistachio nuts, dried figs), maize and maize products and some spices [11-13].

OTA and $\mathrm{AFB}_{1}$ have been classified by the International Agency for Research on Cancer (IARC) as a class $2 \mathrm{~B}$ (possible human carcinogen) and class 1 (human carcinogen), respectively [14,15]. The European Commission (EC) Regulation No 1881/2006 [16] set maximum limits for OTA, AFB 1 and total aflatoxins in different foods. Recently, the European Commission (EC) Regulation No 105/2010 [17], amending Regulation 1881/2006, fixed maximum levels of 20 and $80 \mu \mathrm{g} \mathrm{kg}^{-1}$ for liquorice root, (ingredient for herbal infusion) and for liquorice extracts (for use in liquorice confectionery), respectively (Table 1); this Regulation shall apply from 1 July 2010. The European Food Safety Authority (EFSA), on a request from the EC, adopted an updated scientific opinion relating to OTA in food and fixed a tolerable weekly intake (TWI) of $120 \mathrm{ng} \mathrm{kg}^{-1}$ bw [18]. As regards $\mathrm{AFB}_{1}$, a tolerable daily intake (TDI) was not set, because of its genotoxic properties; therefore, contamination in food should be reduced to the lowest possible level.

The possible presence of OTA in liquorice was pointed out after it was noticed that the toxin occurred in herbal tea, in which liquorice was among the ingredients, but not in black tea [19]. Consequent studies confirmed widespread and high contamination of OTA in foods containing liquorice, sometimes with values exceeding $200 \mu \mathrm{g} \mathrm{kg}^{-1}$ [20-25]; on the contrary, no data are available on AF occurrence in liquorice. The selection of liquorice rhizomes based on homogeneity of colour did not result in a significant reduction of OTA contamination; on the contrary, peeling of roots and processing for the production of liquorice extract and block liquorice significantly reduced the OTA level [26]. However, these processes do not eliminate the problem and a non-negligible OTA contamination can remain in liquorice extract and consequently in liquorice-containing confectionery, sweets widely consumed by children.

In a preliminary survey on a limited number of samples (20) purchased in Italy, we found high levels of OTA in dried liquorice products and limited $\mathrm{AFB}_{1}$ contamination in dried liquorice products and liquorice confectionery (2-10\% of liquorice) [27].The present study reports the results of a further survey, on the incidence and levels of OTA and AFs in these two types of products and evaluates their contribution to OTA and aflatoxin intake in humans. 
Table 1. EU maximum admissible limits for $\mathrm{OTA}, \mathrm{AFB}_{1}$, total aflatoxins (sum of $\mathrm{AFB}_{1}$, $\mathrm{AFB}_{2}, \mathrm{AFG}_{1}, \mathrm{AFG}_{2}$ ) in foodstuffs for direct human consumption.

\begin{tabular}{|c|c|c|c|}
\hline & $\begin{array}{l}\text { OTA } \\
\left(\mu g \mathrm{~kg}^{-1}\right)\end{array}$ & $\begin{array}{l}\mathrm{AFB}_{1} \\
\left(\mu \mathrm{g} \mathrm{kg}^{-1}\right)\end{array}$ & $\begin{array}{l}\text { Sum of } \mathrm{AFB}_{1}, \mathrm{AFB}_{2} \\
\mathrm{AFG}_{1} \text { and } \mathrm{AFG}_{2}\left(\mu \mathrm{g} \mathrm{kg}^{-1}\right)\end{array}$ \\
\hline Cereals for direct human consumption & 3.0 & 2.0 & 4.0 \\
\hline $\begin{array}{l}\text { Groundnuts, nuts and dried fruit for direct human } \\
\text { consumption }\end{array}$ & - & 2.0 & 4.0 \\
\hline $\begin{array}{l}\text { Spices (Capsicum spp., Piper spp., Myristica fragrans, } \\
\text { Zingiber officinale, Curcuma longa) }\end{array}$ & $30^{*}$ & 5.0 & 10.0 \\
\hline Dried wine fruit & 10.0 & - & - \\
\hline Wine and grape juice & 2.0 & - & - \\
\hline Roasted coffee & 5.0 & - & - \\
\hline Soluble coffee & 10.0 & - & - \\
\hline $\begin{array}{l}\text { Processed cereal-based foods and baby foods } \\
\text { for infants and young children }\end{array}$ & 0.50 & 0.1 & \\
\hline Liquorice root & 20 & & \\
\hline Liquorice extract & 80 & & \\
\hline
\end{tabular}

\section{Results and Discussion}

\subsection{Performance of the analytical method}

The samples were initially analysed, both for OTA and for AFs, using HPLC with fluorimetric detection (HPLC-FLD); however, accurate identification and quantification was not possible in some extracts, because of the presence of interfering peaks near those of OTA and $\mathrm{AFB}_{1}$. Therefore, the samples were analyzed by HPLC coupled with mass spectrometry (HPLC-MS/MS). The recovery values were estimated by spiking a blank sample with appropriate volumes of OTA and AF standards, in order to have contamination levels of 2 and $10 \mu \mathrm{g} \mathrm{kg}^{-1}$ for OTA and for each AF. Average recovery values, obtained by HPLC-MS/MS analysis, were above $89 \%$ for OTA and $\mathrm{AFB}_{1}$ (Table 2), and above $86 \%$ for the other AFs.

The limits of detection (LOD) and of quantification (LOQ) were defined at those levels resulting in signal-to-noise ratios of 3 and 10, respectively. The analyte response and the chromatographic noise were both measured from the chromatogram of a blank sample extract $(0.5 \mathrm{~mL})$, to which volumes between 0.1 and $0.5 \mathrm{~mL}$ of OTA and AFs solutions ( 0.066 and $0.115 \mu \mathrm{g} \mathrm{L}^{-1}$, respectively) had been added. The LOD and LOQ values were 0.12 and $0.35 \mu \mathrm{g} \mathrm{kg}^{-1}$ for OTA, 0.25 and $0.60 \mu \mathrm{g} \mathrm{kg}^{-1}$ for each of the four AFs. The calibration curve showed good linearity over the range 0.2-20 pg for OTA and $0.25-2 \mathrm{pg}$ for AFs $(\mathrm{r}>0.998)$. To test for matrix effect, a second calibration curve was generated from standard solutions prepared by dilution with blank purified extract of dried liquorice extract and liquorice confectionery. The $95 \%$ confidence intervals for the slopes and y-intercepts of the two curves overlapped, indicating no significant matrix effect. 
Table 2. Recovery of OTA and $\mathrm{AFB}_{1}$ from artificially contaminated liquorice products.

\begin{tabular}{|c|c|c|c|c|}
\hline & \multirow[b]{2}{*}{$\begin{array}{c}\text { Spike level } \\
\left(\mu \mathrm{g} \mathrm{kg}^{-1}\right)\end{array}$} & \multirow[b]{2}{*}{ Number of analyses } & \multicolumn{2}{|c|}{ Recovery $(\%)$} \\
\hline & & & $\begin{array}{c}\text { Mean } \pm \text { standard } \\
\text { deviation }\end{array}$ & Range \\
\hline \multicolumn{5}{|l|}{ OTA } \\
\hline \multirow[t]{2}{*}{ Dried liquorice extract } & 2 & 4 & $92.2 \pm 1.7$ & $90.1-94.2$ \\
\hline & 10 & 4 & $91.8 \pm 1.5$ & $90.0-93.6$ \\
\hline \multirow[t]{2}{*}{ Liquorice confectionery } & 2 & 4 & $91.0 \pm 1.8$ & $89.1-93.3$ \\
\hline & 10 & 4 & $90.6 \pm 1.6$ & $88.7-92.5$ \\
\hline \multicolumn{5}{|l|}{$A F B_{I}$} \\
\hline \multirow[t]{2}{*}{ Dried liquorice extract } & 2 & 4 & $90.6 \pm 1.8$ & $88.4-92.5$ \\
\hline & 10 & 4 & $90.9 \pm 1.6$ & $89.0-92.8$ \\
\hline \multirow[t]{2}{*}{ Liquorice confectionery } & 2 & 4 & $89.7 \pm 2.3$ & $87.5-91.8$ \\
\hline & 10 & 4 & $89.5 \pm 2.0$ & $87.3-91.5$ \\
\hline
\end{tabular}

Figure 1. Chromatograms (HPLC-MS/MS) of: (a) an OTA standard solution $\left(5.06 \mu \mathrm{g} \mathrm{L}^{-1}\right)$, equivalent to $25.3 \mathrm{pg}$ of OTA injected; (b) a naturally-contaminated dried liquorice extract sample containing $136.9 \mu \mathrm{g} \mathrm{kg}^{-1}$ (equivalent to $34.2 \mathrm{pg}$ of OTA injected); (c) selected fragment ions of OTA, derived from the $404 \mathrm{~m} / \mathrm{z}$ parent ion.
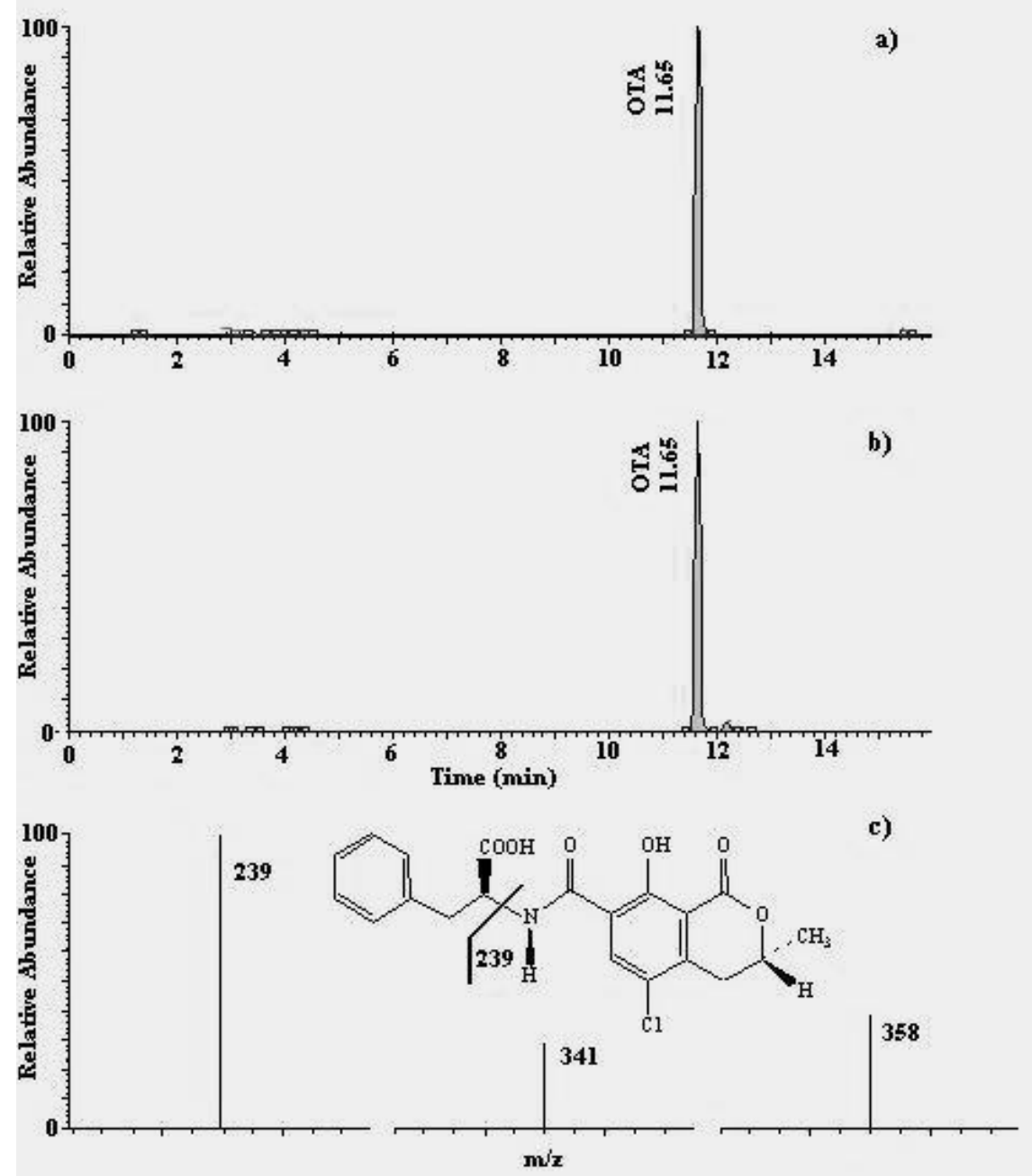
Concerning HPLC-MS/MS analysis, performance criteria fixed by Decision 2002/657/EC [28] were fulfilled completely. Figures 1 and 2 show HPLC-MS/MS chromatograms and the selected fragment ions of a standard solution and a sample of naturally-contaminated liquorice product, for OTA and $\mathrm{AFB}_{1}$, respectively. As regards OTA, the formation of the ions at 358 and 341 are explained by the loss of $\mathrm{H}_{2} \mathrm{O}+\mathrm{CO}(358 \mathrm{~m} / \mathrm{z})$ and $\mathrm{OH}(341 \mathrm{~m} / \mathrm{z})$; the product ion at $239 \mathrm{~m} / \mathrm{z}$ results from molecule cleavage as shown in Figure 1 [20,29]. As regards $\mathrm{AFB}_{1}$, formation of the ions was in agreement with previous works [30-32].

Figure 2. Chromatograms (HPLC-MS/MS) of: (a) an $\mathrm{AFB}_{1}$ and $\mathrm{AFB}_{2}$ standard solution $\left(0.93 \mu \mathrm{g} \mathrm{L}^{-1}\right.$ for each $\mathrm{AF}$ ), equivalent to $4.6 \mathrm{pg}$ of $\mathrm{AFB}_{1}$ and $\mathrm{AFB}_{2}$ injected; (b) a naturallycontaminated dried liquorice extract sample containing $2.19 \mu \mathrm{g} \mathrm{kg}^{-1}$ (equivalent to $0.55 \mathrm{pg}$ of $\mathrm{AFB}_{1}$ injected); (c) selected fragment ions of $\mathrm{AFB}_{1}$ derived from the $313 \mathrm{~m} / \mathrm{z}$ parent ion.
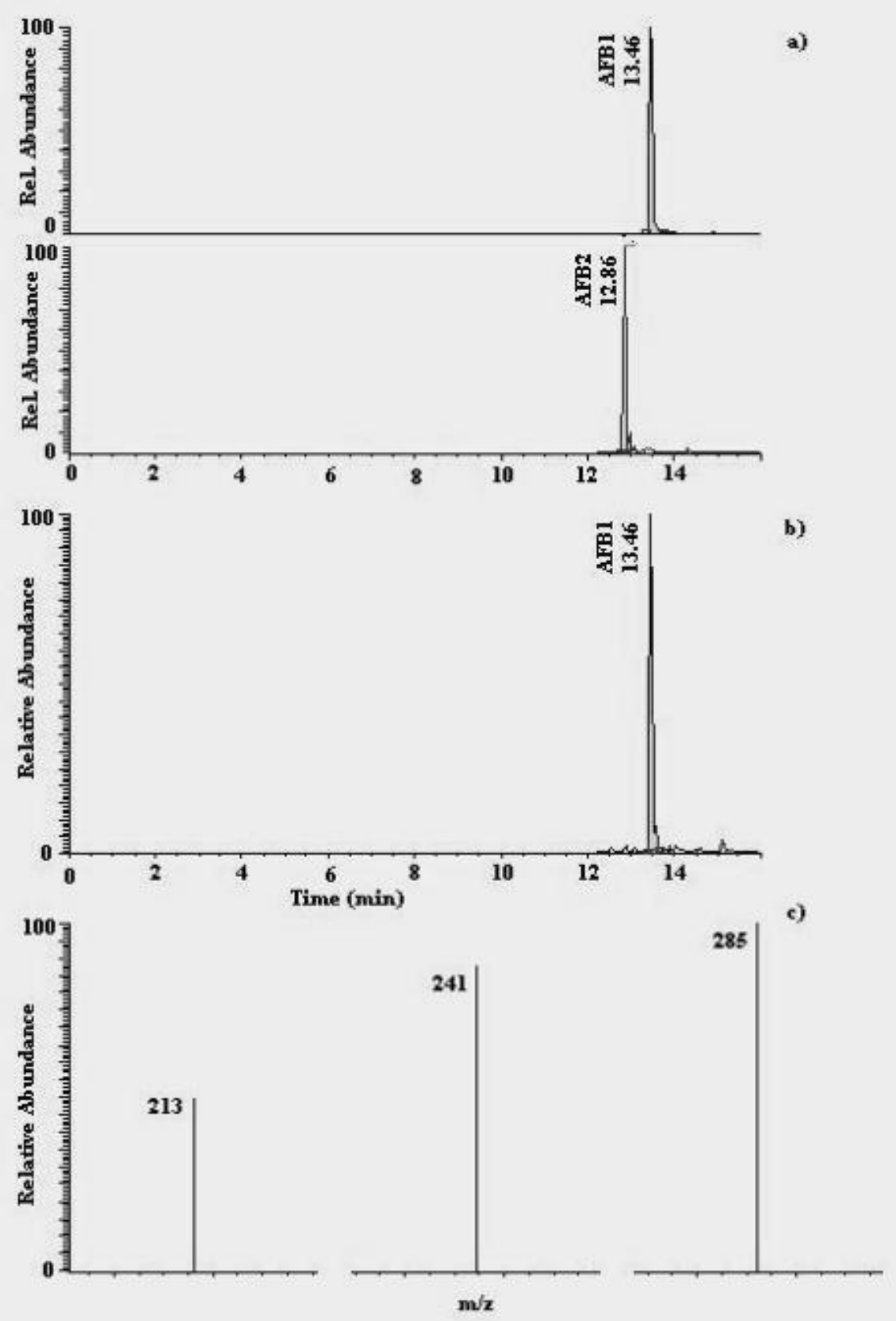
For HPLC-FLD analysis of OTA, LOD and LOQ were 0.05 and $0.15 \mu \mathrm{g} \mathrm{kg}^{-1}$, respectively; the calibration curve showed good linearity over the range $0.1-20 \mathrm{pg}(\mathrm{r}>0.998)$.

The results, corrected for recovery, are reported in Table 3.

\subsection{Ochratoxin A}

OTA was present in 61 samples, with an incidence of $74.4 \%$; among these, 47 (57.3\%) showed an OTA concentration higher than the LOQ. A good correlation between the results obtained by HPLC-FLD and by HPLC-MS/MS was observed at concentrations exceeding $1.0 \mu \mathrm{g} \mathrm{kg}^{-1}(\mathrm{r}=0.98)$. At lower levels HPLC-MS/MS did not always confirm the identity of the peak detected by HPLC-FLD. In fact, in 11 samples (13.4\%) showing an OTA contamination in the range $0.35-1 \mu \mathrm{g} \mathrm{kg}^{-1}$ if measured by HPLC-FLD, the OTA presence was not confirmed by HPLC-MS/MS; in another eight samples $(9.7 \%)$, lower levels were found.

With regard to dried liquorice extract samples, OTA was always detected, also at high concentrations. The incidence of samples with an OTA contamination level higher than $10 \mu \mathrm{g} \mathrm{kg}^{-1} \mathrm{was}$ 71.4\%; among these, five samples (17.8\%) showed a concentration higher than $80 \mu \mathrm{g} \mathrm{kg}^{-1}(87.1$, 113.4, 148.8, 600.5 and $990.1 \mu \mathrm{g} \mathrm{kg}^{-1}$ ), the limit for liquorice extract fixed by the Commission Regulation No 105/2010 [17]. Our data confirmed the widespread and high OTA contamination observed in previous surveys [20-25]. Bresch et al. [20] detected OTA in about 50\% of liquorice roots and in almost all the products $(95 \%)$ obtained after the extraction and concentration process; Arino et al. [21] and Majerus et al. [22] found the toxin in all the samples of dried liquorice extract. In our survey the maximum value was similar to that found in a liquorice root sample $\left(905 \mu \mathrm{g} \mathrm{kg}^{-1}\right)$ by Kabelitz and Sievers [25].

Table 3. Occurrence of OTA and $\mathrm{AFB}_{1}$ in dried liquorice extracts and liquorice confectionery.

\begin{tabular}{|c|c|c|c|c|c|c|c|}
\hline & $\mathbf{n}$ & $\begin{array}{l}\text { Positives > LOD } \\
(>\text { LOQ })\end{array}$ & $\begin{array}{l}\text { Incidence of } \\
\text { positives (\%) }\end{array}$ & $\begin{array}{l}\text { Mean of positives } \\
\left(\mu \mathrm{g} \mathrm{kg}^{-1}\right)\end{array}$ & $\begin{array}{l}\text { Mean of all* } \\
\left(\mu \mathrm{g} \mathrm{kg}^{-1}\right)\end{array}$ & $\begin{array}{l}\text { Median } \\
\left(\mu \mathrm{g} \mathrm{kg}{ }^{-1}\right)\end{array}$ & $\begin{array}{l}\text { Maximum value } \\
\left(\mu \mathrm{g} \mathrm{kg}^{-1}\right)\end{array}$ \\
\hline \multicolumn{8}{|l|}{ OTA } \\
\hline $\begin{array}{l}\text { Dried liquorice } \\
\text { extract }\end{array}$ & 28 & $28(27)$ & 100 & 89.6 & 89.6 & 26.3 & 990.1 \\
\hline $\begin{array}{l}\text { Liquorice } \\
\text { confectionery }\end{array}$ & 54 & $33(20)$ & 61.1 & 1.53 & 0.96 & 0.17 & 8.3 \\
\hline \multicolumn{8}{|l|}{$A F B_{I}$} \\
\hline $\begin{array}{l}\text { Dried liquorice } \\
\text { extract }\end{array}$ & 28 & $5(4)$ & 17.9 & 1.57 & 0.38 & $<\mathrm{LOD}$ & 2.4 \\
\hline $\begin{array}{l}\text { Liquorice } \\
\text { confectionery }\end{array}$ & 54 & $8(5)$ & 14.8 & 2.06 & 0.41 & $<\mathrm{LOD}$ & 7.7 \\
\hline
\end{tabular}

* Mean value was calculated assuming a value of $1 / 2$ LOD for samples <LOD.

Regarding liquorice confectionery products, the contamination was not negligible, as 11 (20.4\%) and four (7.4\%) samples showed a concentration higher than 1 and $4 \mu \mathrm{g} \mathrm{kg}^{-1}$, respectively; the latter could be a possible maximum value for OTA, considering the maximum limit of $80 \mu \mathrm{g} \mathrm{kg}^{-1}$ and a $5 \%$ mean content of liquorice extract in liquorice confectionery products. In previous surveys, Majerus et al. and Bresch et al. detected OTA in 24 out of 26 and 18 out of 19 samples of liquorice 
confectionery sweets respectively (incidence of positives samples $>90 \%$ ); Herrera et al. [24] detected OTA in 75 and $39 \%$ of samples of hard and soft candies, respectively. The mean value in this survey $\left(0.96 \mu \mathrm{g} \mathrm{kg}^{-1}\right)$ resulted similar to those obtained by Majerus et al. $\left(1.1 \mu \mathrm{g} \mathrm{kg}^{-1}\right)$, Bresch et al. $\left(1.3 \mu \mathrm{g} \mathrm{kg}^{-1}\right)$ and Herrera et al. $\left(1.29 \mu \mathrm{g} \mathrm{kg}^{-1}\right)$.

\subsection{Aflatoxins}

Only $\mathrm{AFB}_{1}$ was detected; the contamination resulted very low both for dried liquorice extract and for liquorice confectionery samples. Thirteen samples (15.8\%) showed values higher than $0.25 \mu \mathrm{g} \mathrm{kg}^{-1}$, the LOQ for the HPLC-MS/MS method. In another four samples (4.9\%), $\mathrm{AFB}_{1}$ was detected by HPLC-FLD (LOD $0.1 \mu \mathrm{g} \mathrm{kg}^{-1}$ ) at lower levels. The maximum value was $7.7 \mu \mathrm{g} \mathrm{kg}^{-1}$ (liquorice confectionery sample) and only in three samples was the concentration higher than $2 \mu \mathrm{g} \mathrm{kg}^{-1}$ (EC limit for $\mathrm{AFB}_{1}$ in maize and dried fruit). As regards confectionery products, the low level of $\mathrm{AFB}_{1}$, found in few samples, could be also due to other ingredients.

\subsection{Estimation of OTA dietary intakes by the consumption of liquorice products}

Because of the widespread contamination with OTA, it is of interest to estimate the daily average intake for liquorice products, even if they are not a staple food; however, they are widely consumed, mainly by children. As the contamination levels (median values) in dried liquorice extract and in liquorice confectionery samples were very different, the average daily OTA intake was calculated for both products. Liquorice improves overall health and alleviates a wide range of diseases [33], but its ingestion should be limited for the presence of glycyrrhizinic acid, which, at amounts exceeding $100 \mathrm{mg} \mathrm{day}^{-1}$, can cause different ailments, such as retention of urine and high blood pressure; moreover, the ingestion of liquorice products is contraindicated for diabetics and/or those with high blood pressure $[34,35]$. In dried liquorice extract, glycyrrhizinic acid ranges between 4 and $25 \%$, so it is recommended to eat no more than $0.75 \mathrm{~g}_{\text {day }}{ }^{-1}$ of these products (about 2-3 sweets). Regarding liquorice confectionery, the European Commission carried out a study on north-European populations, that estimated an average daily consumption per person (consumers and non consumers), from 2.7 to $6.8 \mathrm{~g}$; the intake increased to $11.5 \mathrm{~g}$ for high consuming children [36]. Considering the median values of the present survey (26.3 and $0.17 \mu \mathrm{g} \mathrm{kg}^{-1}$ for dried liquorice extract and liquorice confectionery samples, respectively) and an average consumption of 0.75 and $6.8 \mathrm{~g} \mathrm{day}^{-1}$, it was calculated an OTA daily intake of 19.7 and $1.1 \mathrm{ng}$ for dried liquorice extract and liquorice confectionery samples, respectively (corresponding to a weekly intake of 137.9 and $7.7 \mathrm{ng}$ ). The European Food Safety Authority (EFSA) derived a tolerable weekly intake (TWI) for OTA of $120 \mathrm{ng} \mathrm{kg}^{-1} \mathrm{bw}$ [18]; considering a body weight of 70 and $30 \mathrm{~kg}$ for adults and children, respectively, the weekly average exposure for dried liquorice extract resulted equivalent to 1.6 and $3.8 \%$ of the TWI, while for liquorice confectionery to 0.1 and $0.2 \%$. These values indicated that exposure from liquorice confectionery was negligible, in agreement with the study of Herrera et al. [24], which reported values of 0.13 and $0.31 \%$ of the TWI for adults and children, respectively. On the contrary, for a child regularly consuming dried liquorice extract sweets, the intake is not negligible, considering that OTA can be present in many other foods in the diet. 


\section{Experimental Section}

\subsection{Samples}

In years 2006 and 2007, 28 samples of dried extract liquorice and 54 samples of liquorice confectionery (2-10\% of liquorice) were collected from retail outlets in northern Italy; all the products were made in Italy. For each sample, an aliquot of $100 \mathrm{~g}$ or the whole package if the amount was lower, was frozen at $-20{ }^{\circ} \mathrm{C}$ and rapidly milled using a coffee-grinder; then, the sample was homogenized, immediately frozen again and kept at $-20{ }^{\circ} \mathrm{C}$ until the time of analysis. All samples were analysed using both HPLC-FLD and HPLC-MS/MS.

\subsection{Reagents and standards}

HPLC grade acetonitrile, methanol and acetic acid were purchased from Merck (Darmstadt, Germany). Ultrapure water was obtained from a Milli-Q apparatus from Millipore (Milford, MA, USA). The immunoaffinity columns for OTA and AFs were supplied by R-Biopharm Rhône LTD (Glasgow, Scotland, UK). Phosphate buffered saline (PBS) was prepared as per R-Biopharm Rhône LTD ( $\mathrm{NaCl} 8 \mathrm{~g} \mathrm{~L}^{-1}, \mathrm{KCl} 0.2 \mathrm{~g} \mathrm{~L}^{-1}, \mathrm{Na}_{2} \mathrm{HPO}_{4} 1.15 \mathrm{~g} \mathrm{~L}^{-1}, \mathrm{KH}_{2} \mathrm{PO}_{4} 0.2 \mathrm{~g} \mathrm{~L}^{-1}$; $\mathrm{pH}$ 7.4).

OTA and AFs standards were obtained from Sigma-Aldrich (St. Louis, MO, USA). A solution of OTA (40 $\mu \mathrm{g} \mathrm{mL}^{-1}$ in benzene-acetic acid 99:1) was calibrated spectrophotometrically at $333 \mathrm{~nm}$ using the value 5,550 $\mathrm{L} \mathrm{mol}^{-1} \mathrm{~cm}^{-1}$ for the absorption coefficient [37] and stored at $-20{ }^{\circ} \mathrm{C}$ when not in use; working standards were prepared by evaporating an exact volume under a stream of nitrogen and re-dissolving the residue in the mobile phase. Regarding HPLC-MS/MS, eight OTA standards in the range between 0.04 and $4 \mu \mathrm{g} \mathrm{L}^{-1}$ were injected. For each $\mathrm{AF}$, a stock solution of 5-8 $\mu \mathrm{g} \mathrm{mL}^{-1}$ was prepared in benzene:acetonitrile $(98: 2 \mathrm{v} / \mathrm{v}, 2 \mathrm{~mL})$ and stored at $-20{ }^{\circ} \mathrm{C}$. The solutions were calibrated spectrophotometrically at $350 \mathrm{~nm}$, using the values $19,800,20,900,17,100$ and $18,200 \mathrm{~L} \mathrm{~mol}^{-1} \mathrm{~cm}^{-1}$ for the absorption coefficient of $\mathrm{AFB}_{1}, \mathrm{AFB}_{2}, \mathrm{AFG}_{1}$ and $\mathrm{AFG}_{2}$, respectively [38]; the solutions were stored at $-20{ }^{\circ} \mathrm{C}$ when not in use; working standards were prepared by evaporating an exact volume under a stream of nitrogen and re-dissolving the residue in the mobile phase. Regarding HPLC-MS/MS, eight calibrant solutions at individual concentrations of $\mathrm{AFB}_{1}, \mathrm{AFB}_{2}, \mathrm{AFG}_{1}, \mathrm{AFG}_{2}$ between 0.05 and $0.4 \mu \mathrm{g} \mathrm{L}{ }^{-1}$ were injected.

\subsection{Analysis for OTA}

OTA was extracted from a $10 \mathrm{~g}$ portion of sample, with $100 \mathrm{~mL}$ of a mixture of sodium bicarbonate $0.13 \mathrm{M}$-methanol $(50+50 \mathrm{v} / \mathrm{v})$ for $45 \mathrm{~min}$ using a rotary-shaking stirrer. After filtration through a folded filter paper, an aliquot of the filtrate $(5 \mathrm{~mL})$ was diluted with PBS $(50 \mathrm{~mL})$ and purified through an immunoaffinity column (Ochraprep, R-Biopharm Rhône LTD). The column was washed with PBS $(2 \mathrm{~mL})$ and OTA was slowly eluted $\left(0.5 \mathrm{~mL} \mathrm{~min}^{-1}\right)$ with methanol acidified with acetic acid $(98+2 \mathrm{v} / \mathrm{v}, 2.5 \mathrm{~mL})$ into a graduated glass vial: the eluate was concentrated under a gentle stream of nitrogen, brought to $1 \mathrm{~mL}$ with acetonitrile: $2 \%$ acetic acid $(41+59 \mathrm{v} / \mathrm{v})$ and vortex-mixed for few seconds. The extract was filtered (HV $0.45 \mu \mathrm{m}$, Millipore Corporation, Bedford, Massachusetts, USA) before HPLC analysis. 


\subsubsection{HPLC-FLD analysis}

The HPLC system consisted of a Perkin Elmer 200 (Perkin Elmer, Norwalk, Connecticut, USA), equipped with a Jasco AS 1555 sampling system and a FP 1520 fluorescence detector (Jasco Corporation, Tokyo, Japan) set at $333 \mathrm{~nm}$ excitation and $470 \mathrm{~nm}$ emission wavelength. The system was governed by a Borwin 1.5 software (Jasco). A RP-18 column ( $4 \mu \mathrm{m}$ particle size, $125 \times 4 \mathrm{~mm}$ i.d., Merck) was employed at ambient temperature, with a mobile phase of acetonitrile:2\% acetic acid $(41+59 \mathrm{v} / \mathrm{v})$ at $1.0 \mathrm{~mL} \mathrm{~min}^{-1}$. The injection volume was $30 \mu \mathrm{L}$.

\subsubsection{HPLC-MS/MS analysis}

The identification and quantification of OTA were carried out by HPLC-MS/MS analysis. The HPLC-MS/MS system consisted of a LC 1.4 Surveyor pump (Thermo Fisher Scientific, San Jose, CA, USA), a PAL 1.3.1 sampling system (CTC Analitycs AG, Zwingen, Switzerland) and a Quantum Discovery Max triple quadrupole mass spectrometer; the system was controlled by a Excalibur 1.4 software (Thermo-Fisher). After dilution of the purified extracts $(0.1 \mathrm{~mL}$ brought to $0.5 \mathrm{~mL})$ with acetonitrile:water $(60+40 \mathrm{v} / \mathrm{v}$, acidified with $0.4 \%$ acetic acid $)$, OTA was chromatographed on a Betasil RP-18 column ( $5 \mu \mathrm{m}$ particle size, $150 \times 2.1 \mathrm{~mm}$ i.d., Thermo-Fisher) and separated using gradient elution with acetonitrile and water as mobile phase $\mathrm{A}$ and $\mathrm{B}$, respectively (both acidified with $0.4 \%$ acetic acid). The gradient program was as follows: at time zero $40 \%$ solvent A; linear gradient to $75 \%$ solvent A within $8 \mathrm{~min}$, then isocratic for $5 \mathrm{~min}$. The flow rate was $0.2 \mathrm{~mL} \mathrm{~min}^{-1}$. The ionization was carried out with an ESI interface (Thermo-Fisher) in positive mode as follows: spray capillary voltage was $4.0 \mathrm{kV}$, sheath gas and auxiliary gas 30 and 5 psi, respectively; temperature of the heated capillary $270{ }^{\circ} \mathrm{C}$. The mass spectrometric analysis was performed in selected reaction monitoring $(\mathrm{SRM})$. For fragmentation of $[\mathrm{M}+\mathrm{H}]^{+}$ions $(404 \mathrm{~m} / \mathrm{z})$, the argon collision pressure was $1.5 \mathrm{mTorr}$ and the collision energy was 25 and $15 \mathrm{~V}$. The detected and quantified fragment ions were 358, 341 and $239 \mathrm{~m} / \mathrm{z}$. Quantitative determination was performed by a LC-Quan 2.0 software (Thermo-Fisher).

\subsection{Analysis for $A F s$}

AFs were extracted from a $10 \mathrm{~g}$ portion of sample with $100 \mathrm{~mL}$ acetone-water $(70+30 \mathrm{v} / \mathrm{v}) \mathrm{using}$ a rotary-shaking stirrer for $45 \mathrm{~min}$. After filtration through a folded filter-paper, an aliquot of the filtrate (5 mL) was diluted with distilled water $(45 \mathrm{~mL})$ and the solution was purified through an immunoaffinity column (Easi-Extract Aflatoxin, R-Biopharm Rhône LTD). After washing the column with $5 \mathrm{~mL}$ distilled water, AFs were eluted into a graduated glass vial with methanol $(2.5 \mathrm{~mL})$. The eluate, concentrated under a gentle stream of nitrogen, was brought to $1 \mathrm{~mL}$ with acetonitrile:water $(25+75 \mathrm{v} / \mathrm{v})$ and vortex-mixed for few seconds; then, the extract was filtered (HV $0.45 \mu \mathrm{m}$, Millipore), before HPLC analysis.

\subsubsection{HPLC-FLD analysis}

Analysis was performed using an HPLC instrument, consisting of two PU-1580 chromatographic pumps, an AS 1555 sampling system, a FP 1520 fluorescence detector set at $365 \mathrm{~nm}$ excitation and $440 \mathrm{~nm}$ emission wavelength, and a post-column derivatization system (Jasco); the instrument was 
governed by a Borwin 1.5 software (Jasco). A Superspher RP-18 column (4 $\mu \mathrm{m}$ particle size, $125 \times 4 \mathrm{~mm}$ i.d., Merck) was used at ambient temperature, with a mobile phase of water:methanol:acetonitrile $(64: 23: 13 \mathrm{v} / \mathrm{v} / \mathrm{v})$, at $1.0 \mathrm{~mL} \mathrm{~min}{ }^{-1}$. A solution of pyridinium bromide perbromide ( $25 \mathrm{mg}$ in $500 \mathrm{~mL}$ of HPLC-grade water) was used as derivatizing reagent; the flow of the solution was set at $0.1 \mathrm{~mL} \mathrm{~min}^{-1}$ and the volume of the reaction tube was $500 \mu \mathrm{L}$. The injection volume was $30 \mu \mathrm{L}$.

\subsubsection{HPLC-MS/MS analysis}

The identity and quantification of AFs were carried out by HPLC-MS/MS analysis. The HPLC-MS/MS system consisted of a LC 1.4 Surveyor pump (Thermo Fisher Scientific), a PAL 1.3.1 sampling system (CTC Analytics AG) and a Quantum Discovery Max triple quadrupole mass spectrometer; the system was controlled by an Excalibur 1.4 software (Thermo-Fisher). After dilution of the purified extracts $(0.1 \mathrm{~mL}$ brought to $0.5 \mathrm{~mL})$ with acetonitrile-water $(60+40 \mathrm{v} / \mathrm{v}$, acidified with $0.4 \%$ acetic acid), AFs were chromatographed on a Betasil RP-18 column (5 $\mu \mathrm{m}$ particle size, $150 \times 2.1 \mathrm{~mm}$ i.d., Thermo-Fisher) and separated using gradient elution with acetonitrile and water as mobile phase $\mathrm{A}$ and $\mathrm{B}$, respectively (both acidified with $0.4 \%$ acetic acid). The gradient program was as follows: at time zero $15 \%$ solvent $\mathrm{A}$; linear gradient to $65 \%$ solvent $\mathrm{A}$ within 9 min, then isocratic

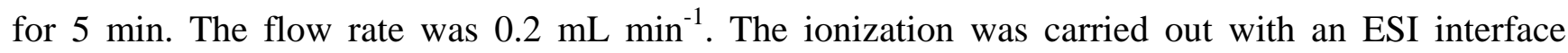
(Thermo-Fisher) in positive mode as follows: spray capillary voltage was $4.0 \mathrm{kV}$; sheath gas and auxiliary gas 41 and 5 psi, respectively; temperature of the heated capillary $270{ }^{\circ} \mathrm{C}$. The mass spectrometric analysis was performed in SRM. For fragmentation of $[\mathrm{M}+\mathrm{H}]^{+}$ions $(313 \mathrm{~m} / \mathrm{z})$, the argon collision pressure was 1.5 mTorr and the collision energy was 33 and $15 \mathrm{~V}$. The detected and quantified fragment ions were 285,241 and $213 \mathrm{~m} / \mathrm{z}$. Quantitative determination was performed by a LC-Quan 2.0 software (Thermo-Fisher).

\section{Conclusions}

On the basis of the results obtained in this survey, the OTA levels in liquorice extract should be continuously monitored, because of the widespread contamination of this product that leads to a nonnegligible OTA presence in liquorice-based confectionery products. There is a need to investigate the origins of this contamination and to apply Good Agricultural Practice principles to cultivation, harvesting and drying of the liquorice roots. With regard to AFs, to our knowledge it is the first time that $\mathrm{AFB}_{1}$ has been detected in liquorice extract samples. Here again, there is a need to investigate the origin of this contamination and the possible presence of the toxin in liquorice root used as an ingredient for herbal infusion.

\section{References}

1. Frisvad, J.C.; Thrane, U.; Samson, R.A. Mycotoxin producers. In Food Mycology. A Multifaceted Approach to Fungi and Food; Dijksterhuis, J., Samson, R.A., Eds.; CRC Press, Taylor \& Francis Group: Boca Raton, FL, USA, 2007; pp. 135-159. 
2. Marquardt, R.; Frohlich, A. A review of recent advances in understanding ochratoxicosis. $J$. Anim. Sci. 1992, 70, 3968-3988.

3. Pleština, R. Nephrotoxicity of ochratoxin A. Food Addit. Contam. 1996, 13 (Suppl.), 49-50.

4. Schlatter, Ch.; Studer-Rohr, J.; Rásonyi, Th. Carcinogenicity and kinetic aspects of ochratoxin A. Food Addit. Contam. 1996, 13 (Suppl.), 43-44.

5. Joint FAO/WHO Expert Committee on Food Additives (JEFCA). Ochratoxin A. In Safety Evaluation of Certain Mycotoxins, Prepared by the Fifty-sixth Meeting of JEFCA. WHO food additives series 47/FAO food and nutrition 74 International Programme on Chemial Safety (IPCS); WHO: Geneva, Switzerland, 2001; p. 281.

6. Benford, D.; Boyle, C.; Dekant, W.; Fuchs, R.; Gaylor, D.; Hard, G.; Mc Gregor, D.; Pitt, J.; Pleština, R.; Shephard, G.; Solfrizzo, M.; Vergere, P.; Walker, R. Ochratoxin A. Safety evaluation of certain mycotoxins in food. In WHO Food Additives; World Health Organization: Geneva, Switzerland, 2001; Series 47, p. 281.

7. Thirumala Devi, K.; Mayo, M.; Gopal-Reddy Emanuel, K.; Larondelle, Y.; Reddy, D.; Reddy, G. Occurrence of ochratoxin A in black pepper, coriander, ginger and turmeric in India. Food Addit. Contam. 2001, 18, 830-835.

8. Pietri, A.; Bertuzzi, T.; Gualla, A.; Piva, G. Occurrence of ochratoxin A in raw ham muscle and in pork products from northern Italy. Ital. J. Food Sci. 2006, 1, 1-8.

9. Zimmerli, B.; Dick, R. Ochratoxin A in table wine and grape-juice: occurrence and risk assessment. Food Addit. Contam. 1996, 13, 655-688.

10. Shephard, G.S. Impact of mycotoxins on human health in developing countries. Food Addit. Contam. 2008, 25, 146-151.

11. Fernandez-Pinto, V.; Patriarca, A.; Locani, O.; Vaamonde, G. Natural co-occurrence of aflatoxin and cyclopiazonic acid in peanuts grown in Argentina. Food Addit. Contam. 2001, 18, 1017-1020.

12. Pietri, A.; Bertuzzi, T.; Pallaroni, L.; Piva, G. Occurrence of mycotoxins and ergosterol in maize harvested over 5 years in Northern Italy. Food Addit. Contam. 2004, 21 (5), 479-487.

13. Galvano, F.; Ritieni, A.; Piva, G.; Pietri, A. Mycotoxins in the human food chain. In Mycotoxins Blue Book; Diaz, D., Ed.; Nottingham University Press: Nottingham, UK, 2005; pp. 187-224.

14. Castegnaro, M.; Wild, C. IARC activities in mycotoxins research. Nat. Toxins 1995, 3, 327-331.

15. International Agency for Research on Cancer (IARC). Some naturally occurring substances, food items and constituents, heterocyclic aromatic amines and mycotoxins. In IARC Monographs on Evaluation of Carcinogenic Risk to Humans; IARC Press: Lyon, France, 1993; Volume 56, p. 245.

16. Commission of the European Communities. Commission Regulation (EC) No 1881/2006 of 19 December 2006 setting maximum levels for certain contaminants in foodstuffs. Off. J. Eur. Union 2006, L364, 5-24.

17. Commission of the European Communities. Commission Regulation (EC) No 105/2010 of 5 February 2010 setting maximum levels for certain contaminants in foodstuffs as regards ochratoxin A. Off. J. Eur. Union 2010, L35, 7-8. 
18. European Food safety Authority (EFSA). Opinion of the scientific panel on contaminants in the food chain on a request from the commission related to ochratoxin A in food. Question No EFSAQ-2005-154, adopted on 4 April 2006. EFSA J. 2006, 365, 1-56.

19. Bresch, H.; Urbanek, M.; Hell, K. Ochratoxin A in coffee, tea and beer. Archiv für Lebensmittelhygiene 2000, 51, 89-94.

20. Bresch, H.; Urbanek, M.; Nusser, M. Ochratoxin A in food containing liquorice. Nahrung 2000b, 44, 276-278.

21. Majerus, P.; Max, M.; Klaffke, H.; Palavinskas, R. Ochratoxin A in Süßholz, Lakritze und daraus hergestellten Erzeugnissen. Deutsche Lebensmittel-Rundschau 2000, 96, 451-454.

22. Arino, A.; Herrera, M.; Estopañan, G.; Juan, T. High levels of ochratoxin A in licorice and derived products. Int. J. Microbiol. 2007, 114, 366-369.

23. Trucksess, M.W.; Scott, P.M. Mycotoxins in botanicals and dried fruits: A review. Food Addit. Contam. 2008, 25, 181-192.

24. Herrera, M.; Herrera, A.; Arino, A. Estimation of dietary intake of ochratoxin A from liquorice confectionery. Food Chem. Toxicol. 2009, 47, 2002-2006.

25. Kabelitz, L.; Sievers, H. Contaminants of medicinal and food herbs with a view to EU regulations. Innovations Food Technol. 2004, November, 25-27.

26. Arino, A.; Herrera, M.; Langa, E.; Raso, J.; Herrera, A. Ochratoxin A in liquorice as affected by processing methods. Food Addit. Contam. 2007, 24 (9), 987-992.

27. Bertuzzi, T.; Gualla, A.; Fortunati, P.; Pietri, A. Indagine sulla presenza di aflatossine e ocratossina A in prodotti a base di liquirizia. In Proceedings of II Conference "Le micotossine nella filiera agro-alimentare”, Rome, Italy, 16-18/10/2006; Rapporti ISTISAN 07/37, pp. 139-142.

28. Commission of the European Communities. Commission Decision (EC) No 657/2002 of 12 August 2002 concerning the performance of analytical methods and the interpretation of results. Off. J. Eur. Union 2002, L221, 8-36.

29. Becker, M.; Degelmann, P.; Herderich, M.; Schreier, P.; Humpf, H. Column liquid chromatography-electrospray ionisation-tandem mass spectrometry for the analysis of ochratoxin.

J. Chromatogr. A 1998, 818, 260-264.

30. Plattner, R.D.; Bennet, G.A.; Stubblefield, R.D. Identification of aflatoxins in dust and urine by liquid chromatography-electrospray ionization tandem mass spectrometry. J. Assoc. Off. Anal. Chem. 1984, 67 (4), 734-738.

31. Edinboro, L.E.; Karnes, H.T. Determination of aflatoxin $B_{1}$ in sidestream cigarettes smoke by immunoaffinity column extraction coupled with liquid chromatography/mass spectrometry. $J$. Chromatogr. A 2005, 1083 (1-2), 127-132.

32. Lattanzio, V.M.T.; Solfrizzo, M.; Powers, S.; Visconti, A. Simultaneous determination of aflatoxins, ochratoxin A and Fusarium toxins in maize by liquid chromatography/tandem mass spectrometry after multitoxin immunoaffinity cleanup. Rapid Commun. Mass Spectrom. 2007, 21, 3253-3261.

33. Fiore, C.; Eisenhut, M.; Ragazzi, E.; Zanchin, G.; Armanini, D. A history of the therapeutic use of liquorice in Europe. J. Ethnopharmacol. 2005, 99, 317-324. 
34. SCF. Reports of the Scientific Committee on Food (29th series), Commission of the European Communities, Food Science and Techniques. Report No EUR 14482 EN; CEC: Luxembourg, 1991.

35. Størmer, F.; Reistad, R.; Alexander, J. Glycyrrhizinic acid in liquorice-evaluation of health hazard. Food Chem. Toxicol. 1993, 31, 303-312.

36. SCF. Opinion of the Scientific Committee on food on glycyrrhizinic acid and its ammonium salt (expressed on 4 April 2003). Directorate-Scientific Opinions SCF/CS/ADD/EDUL/225 Final-10 April 2003. European Commission: Brussels, Belgium.

37. A.O.A.C. Natural Toxins: Ochratoxins. In Official Methods of Analysis, 16th ed.; International Association of Official Analytical Chemists: Arlington, VA, USA, 1995; Chapter 49, p. 38.

38. A.O.A.C. Natural Toxins: Aflatoxins. In Official Methods of Analysis, 18th ed. International Association of Official Analytical Chemists: Gaithersburg, MD, USA, 2005; Chapter 49, p. 4.

(C) 2010 by the authors; licensee MDPI, Basel, Switzerland. This article is an open-access article distributed under the terms and conditions of the Creative Commons Attribution license (http://creativecommons.org/licenses/by/3.0/). 